\title{
Corrosion Deterioration of Steel in Cracked SHCC
}

\author{
Suvash Chandra Paul ${ }^{1,2,3), *}$, and Gideon Pieter Adriaan Greeff van $\mathrm{Zij}^{2)}$
}

\author{
(Received December 15, 2016, Accepted May 15, 2017, Published online September 19, 2017)
}

\begin{abstract}
The presence of cracks is unavoidable in reinforced concrete structures and also a gateway for chloride into concrete, leading to corrosion of steel reinforcing bars. So, crack control, crack width limitation and chloride threshold levels are wellestablished concepts in durability of reinforced concrete structures. This paper reports on accelerated chloride-induced corrosion in cracked reinforced strain-hardening cement-based composites and reinforced mortar beams, both in loaded and unloaded states. Corrosion rates are monitored and loss of mass and yield force, as well as corrosion pitting depth in steel bars are reported. The chloride content at different depths in specimens is also determined through XRF, and through chemical testing of acid and water soluble chloride content by titration. Finally, different relationships are drawn between crack properties, mass loss, yield force, corroded depth and chloride levels at the steel surface for different cover depths. It is found that the crack spacing and free chloride at the steel surface level are best correlated to the corrosion damage in the specimens.
\end{abstract}

Keywords: chloride, corrosion, cracks, steel yield force, pitting depth, mass loss, SHCC.

\section{Introduction}

Cracks in concrete act as pathways for quick ingress of chloride and water. There is evidence that a threshold crack width of about $0.05 \mathrm{~mm}$ exists for water permeability. For cracks wider than this threshold, water permeability increases by orders of magnitude (Wang et al. 1997). Chloride diffusivity has been shown to increase linearly with crack width increase in the range $0.03-0.2 \mathrm{~mm}$ (Djerbi et al. 2008). Little or no chloride appears to be transported through cracks with widths below the lower threshold of $0.03 \mathrm{~mm}$, while the diffusivity stabilises at crack widths beyond the upper threshold $(0.2 \mathrm{~mm})$. Once oxygen also reaches the steel, an electrochemical cell forms and corrosion of steel reinforcement commences. In reinforced concrete structures (RCS) chloride ions act as a catalyst in the localised breakdown of the passive film on the steel surface. The passive film initially forms on steel as a result of the alkaline nature of the pore solution in concrete. A minimum concentration of chlorides on the steel, known as the chloride threshold level, is required to de-passivate the reinforcement and allow corrosion to occur (Angst et al. 2009; Pacheco and

\footnotetext{
${ }^{1)}$ Singapore Centre for 3D Printing, School of Mechanical and Aerospace Engineering, Nanyang Technological University, Singapore, Singapore.

*Corresponding Author; E-mail: suvashpl@ntu.edu.sg

${ }^{2)}$ Department of Civil Engineering, Stellenbosch University, Stellenbosch, South Africa.

${ }^{3)}$ Civil Engineering, School of Engineering, Monash

University Malaysia, Bandar Sunway, Malaysia.

Copyright $\odot$ The Author(s) 2017. This article is an open access publication
}

Polder 2016). Once the steel has been fully de-passivated, the rate of corrosion depends on the availability of oxygen and moisture, as well as structural geometry. After corrosion initiation, corrosion products (iron oxides and hydroxides) form and accumulate. These products have a greater volume than the original iron, which leads to internal stresses and may result in cracking and spalling of the concrete cover (Altoubat et al. 2016; Broomfield 2007). Corrosion initiation periods were investigated by the Huang (2006) in RC containing cracks of various widths. A maximum of 30 days to corrosion initiation was observed in specimens containing $0.025 \mathrm{~mm}$ wide cracks. For a crack width of $0.09 \mathrm{~mm}$, the corrosion initiation period was about 14 days. Note that in this study, the specimens were exposed to a $10 \%$ salt aqueous solution continuously for 49 days of testing. It illustrates that the presence of wider cracks in concrete specimens accelerates the corrosion process and reduces the initiation period. However, in the same study no relationship was found between the corrosion rate and crack widths. The blockage of cracks with the corrosion products, and possible self-healing of cracks may reduce the corrosion rate in time. Another study by Mohammed et al. (2001) on microcell corrosion in cracked concrete found a linear relationship between the corrosion current density and crack widths in the range $0.1-0.7 \mathrm{~mm}$ at early stages. In a later stage, after 15 weeks of testing, no relationship was found.

In the chloride-induced corrosion process, a certain amount of chlorides must reach the steel to initiate the corrosion process. This value is significant because it is an input parameter in the service life design and service life prediction models of RCS. However, it is still uncertain what the threshold amount of chloride for corrosion initiation is, and thus guidelines for durability design, and preventative repair of RCS are unclear. Hausmann (1967) suggested that the 
critical chloride content ( $\%$ by cement wt) is about 0.06-1.0\%, while Pettersson (1993) and Schiessl and Raupach (1997) proposed ranges of $0.9-1.8 \%$ and $0.48-2.02 \%$. The threshold chloride content depends on several factors like the concrete $\mathrm{pH}$ level, cement and admixture types and water/binder ratio. Another important issue is whether all the chloride inside concrete contributes to the corrosion process. Depending on the matrix binding capacity, some chloride may be bound in matrix compositions and do not contribute to the corrosion. So, the amount of free chloride in concrete may be more representative than the total chloride content. German and Zaborski (2011) suggested a threshold value for free chloride of about $0.35 \%$ (by concrete wt) in concrete. For the service life prediction of RCS, time to initiation of corrosion is typically modelled by Fick's Law (Liang et al. 2009; Tang et al. 2015). The challenge in corrosion modelling is rigorous calibration at the hand of sufficiently large experimental data sets, as well as field validation.

The availability of research data on corrosion in fibre reinforced concrete (FRC) is also limited and not thoroughly understood due to the complex mechanism of corrosion itself (Yoo and Yoon 2016). A particular class of FRC is discussed in this paper, namely strain-hardening cementbased composites (SHCC) (Li 2012). The main feature of SHCC is the formation of multiple fine cracks and increased or maintained tensile resistance upon increased deformation whilst more cracks appear. Limited field and laboratory data exist for a new material like SHCC, and embedded steel bar reinforcement (R/SHCC), and only limited researches have been performed on total chloride content and corrosion in SHCC (Sahmaran et al. 2008; Kobayashi et al. 2010; Mihashi et al. 2011; Wittmann et al. 2011; Kobayashi and Rokugo 2013; Paul and van Zijl 2014, 2016).

SHCC and R/SHCC have the ability to form multiple cracks with limited crack widths during the strain-hardening phase (Paul and van Zijl 2013). It is further known that crack width and cover depth play an important role in corrosion of the steel reinforcing (Bashir et al. 2017; Soltani et al. 2013). However, what is unknown is the effect of crack spacing and whether an optimum range of crack spacing can be found that will limit the corrosion rate. Therefore it is the aim here to investigate the effect of crack spacing on chloride-induced corrosion of R/SHCC. This research paper presents the test program and results of accelerated chloride-induced corrosion of pre-cracked R/SHCC specimens with three levels of cover depths, and one level of steel bar reinforcement. As reference, reinforced mortar $(\mathrm{R} /$ mortar) specimens were also made with two different cover depths. Results are presented of laboratory tests over a minimum of 6 months to a maximum of 2 years of cyclic wetting and drying with chloride aqueous solution, on a total of $64 \mathrm{R} / \mathrm{SHCC}$ and $\mathrm{R} /$ mortar beam specimens. The corrosion rate, consequences of corrosion of steel bars in terms of mass loss and pitting depths, and total and free chloride profiles are studied. As far as the authors could establish, these are the first reports of free versus total chloride in SHCC, as are the proposed relations between loss of mass and resistance, as well as pitting depths in steel bars in R/SHCC. The outcome of this research is intended to contribute to durability design guidelines with respect to chloride-induced corrosion in R/SHCC.

\section{Research Background}

Previous studies on corrosion of R/SHCC specimens found that little or no corrosion can be seen in the specimens, compared with significant corrosion observed in comparative $\mathrm{R} /$ mortar or reinforced steel fibre reinforced cementitious composites (R/SFRC) (Kobayashi et al. 2010; Mihashi et al. 2011; Kobayashi and Rokugo 2013). After 60 days of accelerated chloride exposure (5 min spraying with $3 \% \mathrm{NaCl}$ aqueous solution every $6 \mathrm{~h}$ ), Kobayashi et al. (2010) found no sign of corrosion discoloration on the surface of steel in cracked $(0.02-0.06 \mathrm{~mm}$ crack widths) patched specimens made from high performance fibre reinforced cement composites (HPFRCC) with minimum of 0.75 to maximum $1.5 \%$ polyethylene (PE) fibre content. Mihashi et al. (2011) reported that only $11.8 \%$ of steel bar surface area was corroded, but with zero corrosion depth in hybrid fibre reinforced cementitious composite (HFRCC) specimens, compared with $100 \%$ corroded surface area and $3.1 \mathrm{~mm}$ corroded depth in reference mortar specimens. In their case, steel fibres were combined with polymeric fibre. The steel fibre acted as sacrificial anode, whereby rebar corrosion was significantly reduced. In this case specimens were subjected to a $3 \% \mathrm{NaCl}$ solution by cyclic wetting and drying, while a potential of $3 \mathrm{~V}$ was applied continuously to the specimens for a period of about 1 year. In neither of these researches information of the loss of steel bar yield force due to corrosion was reported.

In a recent work it was found that corrosion reduces the capacity of steel bars in SHCC (Paul and van Zijl 2016), in which pitting corrosion could also be observed. Sahmaran et al. (2008) investigated the loss of flexural load capacity due to accelerated corrosion in both R/SHCC and R/mortar specimens. Reinforced specimens were kept in $5 \% \mathrm{NaCl}$ solution for a minimum of $25 \mathrm{~h}$, to a maximum of $300 \mathrm{~h}$, while a potential of $30 \mathrm{~V}$ was applied to the steel in both the SHCC and mortar specimens. Four-point bending was performed on the specimens after a period of 25, 50, 75, 100 and $300 \mathrm{~h}$ of accelerated corrosion. In mortar specimens, $37 \%$ lower load capacity was found after $25 \mathrm{~h}$ of exposure than in control specimens (without any applied current). No significant change in flexural resistance was found in the $\mathrm{R} / \mathrm{SHCC}$ specimens after $50 \mathrm{~h}$ of exposure. After $300 \mathrm{~h}$ of exposure, more than $55 \%$ loss in flexural capacity was found in $\mathrm{R} / \mathrm{SHCC}$, but in $\mathrm{R} /$ Mortar an $85 \%$ loss was found after just $75 \mathrm{~h}$ of exposure. In a similar type of experiment performed by Paul et al. (2017) also found lower corrosion mass loss in R/SHCC specimens when compared with $\mathrm{R} /$ Mortar specimens. In none of the researches mentioned here information about the number of cracks, crack spacing and their influence on corrosion deterioration was reported.

It should be noted that the electrically enhanced corrosion exposure as applied by Mihashi et al. (2011) and Sahmaran 
et al. (2008) replicates specific, aggressive corrosion conditions. A purely cyclic wetting-drying chloride exposure and a Coulostatic corrosion measuring technique have been performed by several researchers and are followed here. It is argued to be a replication of in situ corrosion in coastal regions (Glass 1995; Gonzalez et al. 2001; Andrade and Alonso 2004). The applied current and duration in the Coulostatic method is miniscule, causing negligible influence on the internal electrochemical corrosion mechanism in the specimens.

\section{Materials and Test Methods}

\subsection{Mix Design of SHCC}

The mix ingredients and proportions are shown in Table 1. Two different types of sand and cement were used. A fine sand (FS-SHCC) with fineness modulus (FM) of 1.9 and local, natural, coarse sand (CS-SHCC) with FM of 3.3 were used. Polyvinyl alcohol (PVA) fibres with length $12 \mathrm{~mm}$ and diameter $0.04 \mathrm{~mm}$ were used.

\subsection{Specimen Preparation for Corrosion Testing}

The size of beam specimens prepared for one series of beams, i.e. FS2, CS2, FM1 and CM1 was $100 \times$ $100 \times 500 \mathrm{~mm}$, with a single steel reinforcing bar inside. Three R/SHCC specimens were prepared for each of three cover depths 15, 25 and $35 \mathrm{~mm}(\mathrm{C} 15, \mathrm{C} 25$ and C35), for both types of sand, i.e. in total 18 specimens. In case of mortar, only $15 \mathrm{~mm}$ cover depth was chosen; i.e. in total 6 $\mathrm{R} /$ mortar specimens were made. In all specimens a $10 \mathrm{~mm}$ diameter (Y10) high tensile ribbed bar (B1) with a tensile yield stress of about $510 \mathrm{MPa}$ was used. Electrical connection for corrosion testing was facilitated by letting the steel protrude at the top of one series of specimens (see Fig. 1a). Note that in these specimens a stainless plate $(15 \mathrm{~mm}$ thick and $150 \mathrm{~mm}$ long) was used as a counter electrode (CE). For FS31, FS32 and FM2 the beam specimen size was $80 \times 100 \times 490 \mathrm{~mm}$, also with a single Y10 bar (see Fig. 1c). Here a $5 \mathrm{~mm}$ stainless steel with the same length as $\mathrm{B} 1$ was cast into the specimens as a $\mathrm{CE}$, protruding $5 \mathrm{~mm}$ from each beam end - see Fig. 1b-d. The three cover depths were also used for FS31 in two levels of deflection, giving in total 18 specimens (nine for each level of deflection) for FS31. For FS32 and FM2 specimens, only C15 and C25 cover depths were used. A total of 22 specimens were made from both FS32 and FM2. Details of specimens FS32 and FM2 are shown in Table 2, and full details can be found in Paul (2015).

\subsection{Method of Forming Cracks in the Specimens}

Three-point flexural testing was performed in the specimens for creating cracks in FS2 and CS2 specimens. In this regard, specimens were loaded up to a vertical deflection of $3.5 \mathrm{~mm}$ (D3.5) in a Zwick Z250 materials testing machine (MTM) and then unloaded. In case of FM1 and CM1, specimens were loaded to a deflection of only $1.5 \mathrm{~mm}$ (D1.5). The number of cracks and crack widths were recorded. FS31 specimens were loaded up to two different levels of vertical deflections $5 \mathrm{~mm}$ and $7 \mathrm{~mm}$ (D5 and D7) respectively in the Zwick Z250 MTM, in order to study the effect of two different crack patterns. After unloading from the Zwick, all FS31 specimens were placed in special steel frames for sustained loading at the same level of deflections (D5 and D7) by tightening the bolts on both ends of each specimen as shown in Fig. 1c. In case of FS32 and FM2, cracks were formed by making notches in the specimens as shown in Table 2 and then specimens were placed and cracked in similar steel frames as FS31 specimens. The FS32 specimen cracks were formed while measuring the deformation over a central $100 \mathrm{~mm}$ gauge length on the notched surface as shown in Fig. 1c. Details of specimen surface strain and the number of notches are shown in Table 2. Figure $2 \mathrm{a}$ shows the way in which the number of crack and crack spacing were measured in the specimen and Fig. 2b shows the pitting depth measurement in the corroded steel bars which will be discussed in the research results section.

\subsection{Corrosion Test Setup}

In this study the cracked specimens were subjected to the cyclic wetting (3 days) with $3.5 \% \mathrm{NaCl}$ aqueous solution,

Table 1 Amount of materials $\left(\mathrm{kg} / \mathrm{m}^{3}\right)$ used in this research.

\begin{tabular}{c|c|c|c|c|c|c|c|c|c}
\hline Type & Id $^{\mathrm{a}}$ & Cement $^{\mathrm{b}}$ & Fly-ash & Sand $^{\mathrm{c}}$ & Water & Fibre (\%) & SP & VMA & AEA \\
\hline \hline FS-SHCC & FS2 & $392(42.5)$ & 674 & 553 & 392 & 2.01 & 1.99 & 0.54 & 0.54 \\
\hline FS-SHCC & FS31 \& FS32 & $392(52.5)$ & 674 & 553 & 392 & 2.01 & 1.99 & 0.54 & 0.54 \\
\hline CS-SHCC & CS2 & $392(42.5)$ & 674 & 553 & 392 & 2.01 & 1.99 & 0.54 & 0.54 \\
\hline FS-Mortar & FM1 & $401(42.5)$ & 688 & 565 & 401 & - & - & 1.0 & - \\
\hline FS-Mortar & FM2 & $401(52.5)$ & 688 & 565 & 401 & - & - & 1.0 & - \\
\hline CS-Mortar & CM1 & $401(42.5)$ & 688 & 565 & 401 & - & - & 1.0 & - \\
\hline
\end{tabular}

\footnotetext{
a These Id numbers are used in the text and graphs to introduce the different SHCC and mortar types used in this research work.

b CEM I 41.5 and 52.5 cement types are indicated between brackets.

c The maximum sand particle sizes are $0.30 \mathrm{~mm}$ in find sand and $1.70 \mathrm{~mm}$ in coarse sand.

$S P$ super plasticizer, $V M A$ viscosity modifying agent, $A E A$ air entraining agent.
} 
(a)

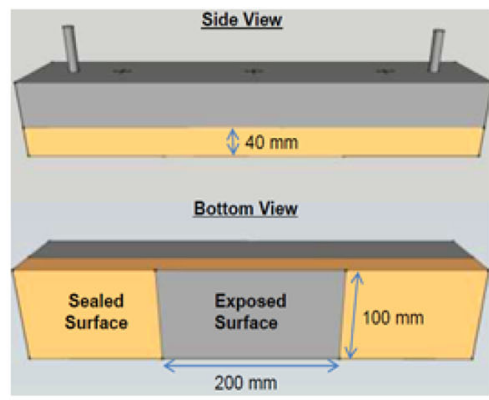

(b)

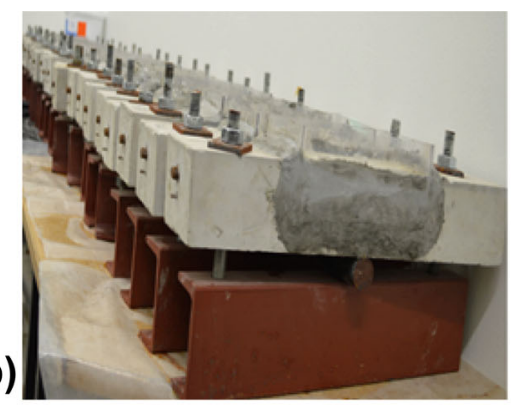

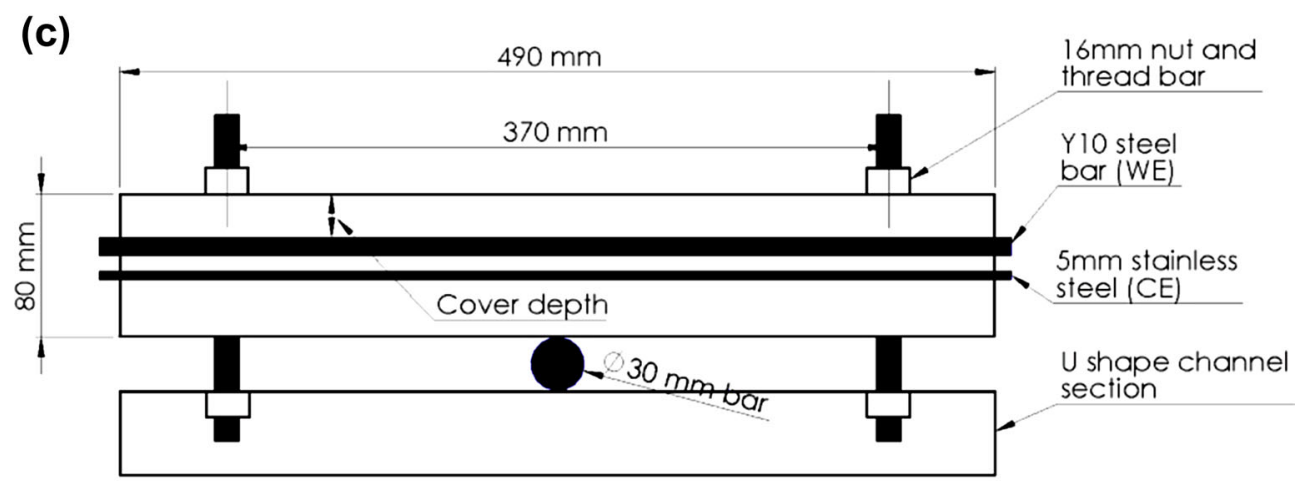

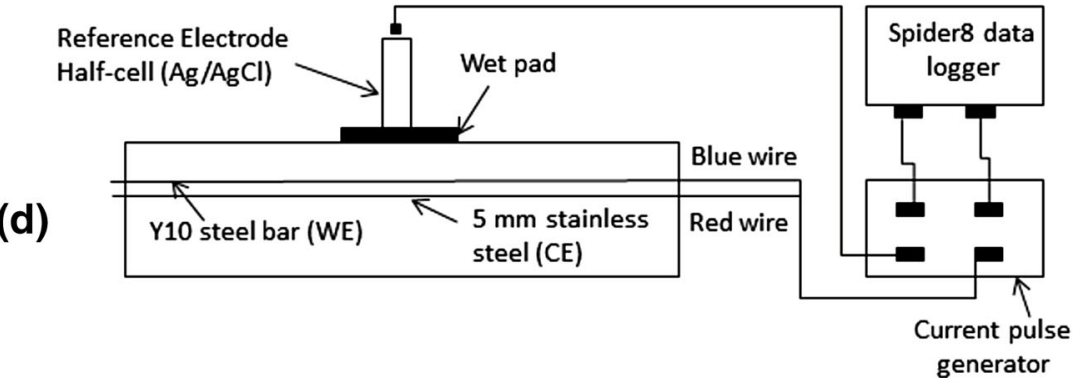

Fig. 1 a FS2, CS2, FM1 and CM1 specimens' preparation for corrosion testing; b FS31, FS32 and FM2 specimens for corrosion test in chloride exposure by means of ponding; c FS31, FS32 and FM2 specimens under sustained load and d corrosion rate measuring technique using a Coulostatic technique.

Table 2 Number of specimens, number of cracks and crack widths in FS32 and FM2.

\begin{tabular}{|c|c|c|c|c|}
\hline Type & Cover $(\mathrm{mm})$ & $\mathrm{Nr}$ of specimens & $\mathrm{Nr}$ of notches/cracks ${ }^{\mathrm{a}}$ & Deformation $(\mathrm{mm})^{\mathrm{b}}$ \\
\hline \multirow[t]{6}{*}{ FS32 } & \multirow[t]{3}{*}{$15(\mathrm{C} 15)$} & 3 & $1(\mathrm{~N} 1)$ & 0.30 \\
\hline & & 3 & $3 @ 40$ mm (N3) & 0.90 \\
\hline & & 3 & $5 @ 20$ mm (N5) & 1.50 \\
\hline & \multirow[t]{3}{*}{$25(\mathrm{C} 25)$} & 3 & $1(\mathrm{~N} 1)$ & 0.30 \\
\hline & & 3 & $3 @ 40$ mm (N3) & 0.90 \\
\hline & & 3 & $5 @ 20$ mm (N5) & 1.50 \\
\hline \multirow[t]{2}{*}{ FM2 } & $15(\mathrm{C} 15)$ & 2 & $1(\mathrm{~N} 1)$ & 0.15 \\
\hline & $25(\mathrm{C} 25)$ & 2 & $1(\mathrm{~N} 1)$ & 0.15 \\
\hline
\end{tabular}

\footnotetext{
${ }^{a}$ Notches of $3 \mathrm{~mm}$ wide and $10 \mathrm{~mm}$ deep were sawn to create artificial cracks in the middle of each specimen, as shown in Fig. 1c.

b During pre-cracking, the deformation was controlled to the value shown over a central $100 \mathrm{~mm}$ gauge length.
}

followed by drying (4 days). FS2, CS2, FM1 and CM1 specimens were subjected to capillary absorption in unloaded state (up to 108 weeks for SHCC and 85 weeks for mortar). Note that, only one directional capillary absorption of the chloride solution through the cracked face of specimens was allowed. In this case, the central $200 \mathrm{~mm}$ cracked length of each specimen was placed in contact with chloride solution, and other surfaces were sealed. In contrast, a ponding method was followed in case of FS31 (up to 57 weeks), FS32 (up to 28 weeks) and FM2 (up to 28 weeks) on specimens in the loaded state. Here a $200 \mathrm{~mm}$ long and $100 \mathrm{~mm}$ wide pond was made on the cracked 


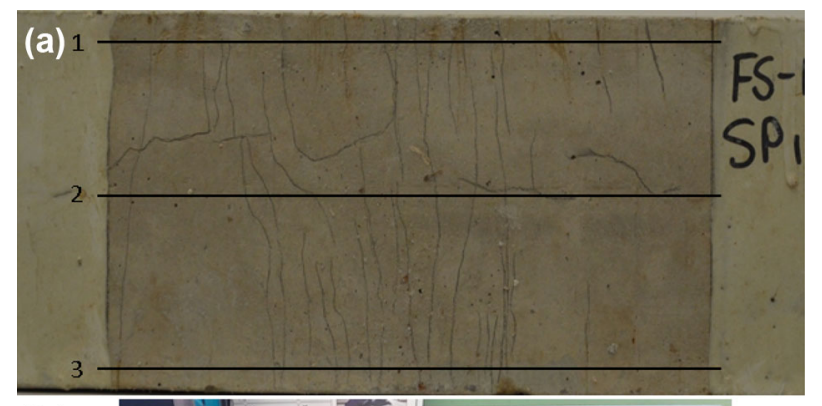

(b)

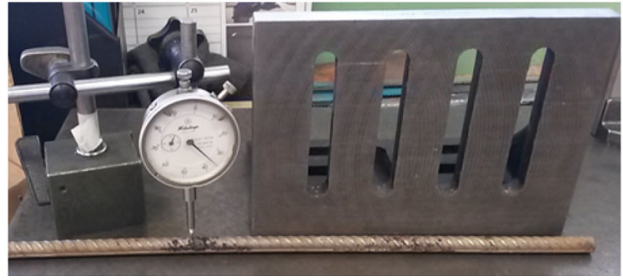

Fig. 2 a Method of determining the crack properties and b determining the pitting depths in the corroded steel bars.

surface of each specimen by non-absorbent plastic as shown in Fig. 1b. All the connections between plastic and the specimen surface were sealed to prevent leakage.

A Coulostatic method was used to measure the corrosion rate. It replicates the Randles circuit, a type of polarisation measuring technique, where a small amount of a known current $(\Delta I)$ is passed through the steel for a known amount of time $(\Delta t)$ while the potential decay $(\Delta E)$ is observed. The polarisation resistance $\left(R_{p}\right)$ of the concrete can then be determined from the $\Delta I / \Delta E$ ratio. The Y10 steel reinforcing bar acted as the working electrode (WE), the stainless steel as the $\mathrm{CE}$, and an $\mathrm{Ag} / \mathrm{AgCl}$ half-cell was used as the reference electrode as seen in Fig. 1d. For the corrosion rate measurement, a Spider8 data logger was used while a current of $4 \mathrm{~mA}$ was applied to each of the specimens for a period of $5 \mathrm{mS}$ by a laboratory built current pulse generator. The reading from each specimen was collected on the last day of each wet and dry cycle. Note that in the case of FS31 specimens with $15 \mathrm{~mm}$ cover, lower perturbation was found for the $4 \mathrm{~mA}$ applied current and as a result a different current $(10 \mathrm{~mA})$ was applied for a $6 \mathrm{mS}$ time period for these specimens.

Once $R_{p}$ is known, the corrosion current $\left(I_{\text {corr }}\right)\left(\mu \mathrm{A} / \mathrm{cm}^{2}\right)$ and from that corrosion rate $\left(V_{\text {corr }}\right)(\mathrm{mm} / \mathrm{year})$ can be determined. So during corrosion testing, if no further current is applied to the steel bar, the potential decays can be represented exponentially with time as follows:

$$
\eta_{t}=\eta_{0} \exp \left(\frac{-t}{\tau_{c}}\right)
$$

where $\eta_{o}$ is the initial potential shift and $\eta_{t}$ the potential shift $(\Delta E)$ at time $t . R_{p}$ is then obtained from the time constant $\left(\tau_{c}\right)$ and interfacial capacitance $(C)$ as follows:

$$
R_{p}=\frac{\tau_{c}}{C}
$$

$$
\begin{aligned}
& I_{\text {corr }}=\frac{B}{R_{p}} \\
& V_{\text {corr }}=0.0116 I_{\text {corr }}
\end{aligned}
$$

where $\eta_{0}$ and $\tau_{c}$ values can be determined by fitting an exponential function to the perturbation $(\mathrm{mV})$ vs time $(\mathrm{sec})$ curve. $B$ is the Stern-Geary constant varying from 26 to $52 \mathrm{mV}$ depending on whether passive or active corrosion is occuring. In this research project the $B$ value was considered to be $26 \mathrm{mV}$. This corrosion rate measuring technique was broadly explained by Glass (1995); Gonzalez et al. (2001); Andrade and Alonso (2004).

After a certain period of cyclic wetting and drying exposure, some of the specimens were broken to observe actual corrosion in the steel bar. The outcomes like loss of rebar tensile yield force and pitting depths were then estimated and compared with experimental outcomes. In this regard, Eqs. (5-6) were used to estimate uniformly corroded depth $\left(d_{c}\right)$ and change in rebar yield force due to uniform cross section reduction $\left(\Delta F_{y}\right)$ as follows:

$$
\begin{aligned}
d_{c}(t) & =d_{c 0}+\int_{0}^{t} V_{\text {corr }} d t \\
& =d_{c 0}+\sum_{i=1}^{N_{t}} \frac{1}{2}\left(V_{\text {corr }}+V_{\text {corr }, i-1}\right)\left(t_{i}-t_{i-1}\right) \\
\Delta F_{y}(t) & =\frac{\pi \sigma_{y}}{4}\left\{d_{s}^{2}-\left[d_{s}-2 d_{c}(t)\right]^{2}\right\}
\end{aligned}
$$

with $d_{c 0}$ the initial corroded depth, $t_{i}$ the corroding period, $\rho_{s}$ the steel density, $d_{s}$ and $L_{s}$ the steel diameter and length (here assumed to be the full $500 \mathrm{~mm}$ ) and $\sigma_{y}$ is the steel nominal yield stress. Note that only for FS32 and FM2 the rebar mass loss was determined by subtracting the weight measured after testing from the initial weight. Note that Eq. (6) does not consider stress concentrations due to the geometrical changes caused by pitting corrosion.

\subsection{Method of Determining Chloride Content}

Chloride penetration profiles were drawn for both $\mathrm{R} / \mathrm{SHCC}$ and $\mathrm{R} /$ mortar specimens after a certain period of accelerated testing. More than 20 specimens were chosen from different SHCC and mortar types after different exposure periods. Chloride profiles were then obtained by drilling from the exposed surface in layers of $3 \mathrm{~mm}$ each, up to a depth of $45 \mathrm{~mm}$ in most specimens. A $16 \mathrm{~mm}$ drill was used to collect powder samples at the different layers in specimens. For a single layer, a minimum of $6 \mathrm{~g}$ powder sample was collected. Powder samples were obtained from at least 4-6 different drilled positions in a specimen, in order to collect the required sample size. All the drillings were performed on cracked positions, for the powder samples to be representative of cracked regions in the specimens (Paul 2015). So, the chloride content obtained here is one-dimensional, and it is the average value of different cracked positions in a single layer. X-ray fluorescence (XRF) was 
used to determine the total chloride content in each $6 \mathrm{~g}$ powder sample. Chemical analysis was also used to determine both total and free chloride content in each layer. For these chemical analyses the RILEM TC 178-TMC (2002a, b) recommendations were followed.

\section{Research Results}

The slump flow value and mechanical properties of ultimate compressive strength $\left(f_{c u}\right)$ and E-modulus $(E-m o d)$ of SHCC and mortar specimens at the age of 28 days are shown in Table 3. The ultimate uniaxial tensile strength $\left(f_{u, s t}\right)$, first cracking strength $\left(f_{c r, s t}\right)$ and ultimate tensile strain $\left(\varepsilon_{u, s t}\right)$ of dumbbell shaped specimens at 14 days from different SHCC mixes are also shown in Table 3. In Table 3 no significant difference in strength can be observed for SHCC with fine and coarse sand. However, a significantly reduced ultimate tensile strain is found for SHCC containing coarse sand. This may be due to the irregular distribution of fibre caused by the larger particles of coarse sand in a small dumbbell section. Also for the particular mix design used in this study, the target compressive strength of SHCC was in a range of $25-28 \mathrm{MPa}$, and a tensile strain capacity of $1-2 \%$.

\subsection{Flexural Cracks in the R/SHCC Specimens}

Figure $3 \mathrm{a}, \mathrm{b}$ show the crack properties, including average crack width $(\mathrm{ACW})$ and maximum crack width $(\mathrm{MCW})$ in the R/SHCC specimens for different cover depths. Larger crack widths were found in specimens with $\mathrm{C} 15$ and this trend was clearer at higher level of deflections in the specimens (Fig. 3b). Although a scatter was noticed for C35 specimens at lower deflection (FS2 and CS2), it appears that there is no significant difference in crack widths for cover depths of $\mathrm{C} 25$ and $\mathrm{C} 35$.

\subsection{Corroded Depth in R/SHCC and R/Mortar Specimens}

Corroded depths calculated from Eq. (5) in different $\mathrm{R} / \mathrm{SHCC}$ and $\mathrm{R} /$ mortar specimens are shown in Fig. $4 \mathrm{a}-\mathrm{d}$. In all cases specimens with $\mathrm{C} 15$ show larger corroded depths. The higher corrosion in the $\mathrm{C} 15$ specimens can be explained by the shorter distance for both chloride and oxygen to penetrate to the steel level. For interpretation of the higher corroded depths of R/FS31 specimens with C15 in Fig. 4b, the application of higher current $(10 \mathrm{~mA})$ for a longer period (6 $\mathrm{mS}$ ) should be kept in mind, as mentioned in Sect. 3.4. It is also worth mentioning that corrosion rate measurements in the FS2, CS2, FM1 and CM1 specimens were started later, while others were taken from the beginning. The corroded depths of these specimens do not reflect the total values since the $d_{\mathrm{c} 0}$ value in Eq. (5) was set to zero at the start of corrosion rate measuring. No significant difference was found in the corroded depths for different sand types and also for $\mathrm{C} 25$ and $\mathrm{C} 35$ specimens. This can be explained by the similar strain-hardening behaviour in terms of strength and cracks in FS2 and CS2 specimens. Further research with different grain sizes of CS is recommended to come up with solid conclusion.

Figures $5 \mathrm{a}-\mathrm{c}$ show the relationships between uniformly corroded depths Eq. (5), actual pitting depths measured in the steel bars, loss of steel bar yield force obtained from tensile testing, and cover depths in $\mathrm{R} / \mathrm{FS} 2$ and $\mathrm{R} / \mathrm{CS} 2$ specimens. The results show a power relationship between the corroded depths and cover depths. The loss of steel yield force was found to be exponentially related to the cover depths in the R/SHCC specimens. It must be kept in mind that the loss of yield force may depend strongly on position, size and shape of the pitting corrosion.

\subsection{Visual Observation of Corrosion Damage}

Corrosion damage in the steel bars in both R/SHCC and $\mathrm{R} /$ mortar specimens was also observed visually after being removed from the specimens. Different SHCC and mortar specimens were broken after different durations of chloride exposure. Interestingly, because of multiple fine cracks, in most FS2, CS2 and FS31 specimens more distributed corrosion (also called general corrosion) was observed as it is shown in Fig. 6. A similar trend was also found in a study by Blagojević (2016). This is postulated to be a result of microcell corrosion, for which it is known that the cathode to anode area ratio is small, and as a result the severity of corrosion is reduced. Concentration of chloride ions is likely not localized in SHCC due to the multiple fine and finely spaced cracks in SHCC, so the corroded depths caused by the ions are not deep. In this case the capacity of steel bar is not reduced significantly. Multiple fine cracks and smaller crack spacing of SHCC (see Fig. 6a) are believed to be the main reason for micro-cell corrosion in $\mathrm{R} / \mathrm{SHCC}$ specimens.

Table 3 SHCC and mortar fresh and mechanical properties.

\begin{tabular}{|c|c|c|c|c|c|c|}
\hline Id & Slump (mm) & $f_{c u}(\mathrm{MPa})$ & $E-\bmod (\mathrm{GPa})$ & $f_{u, s t}(\mathrm{MPa})$ & $f_{c r, s t}(\mathrm{MPa})$ & $\varepsilon_{u, s t}(\%)$ \\
\hline FS2 & $170-200$ & 25 & 14 & 2.6 & 2 & 2.2 \\
\hline FS31 \& FS32 & $180-200$ & $24-28$ & $13-14$ & $2.2-2.5$ & $1.6-1.8$ & $1.6-2.0$ \\
\hline $\mathrm{CS} 2$ & $195-225$ & 23 & 13 & 2.01 & 1.8 & 1.2 \\
\hline FM1 \& FM2 & $200-220$ & $26-31$ & $15-17$ & - & - & - \\
\hline CM1 & $220-225$ & 27 & 17 & - & - & - \\
\hline
\end{tabular}



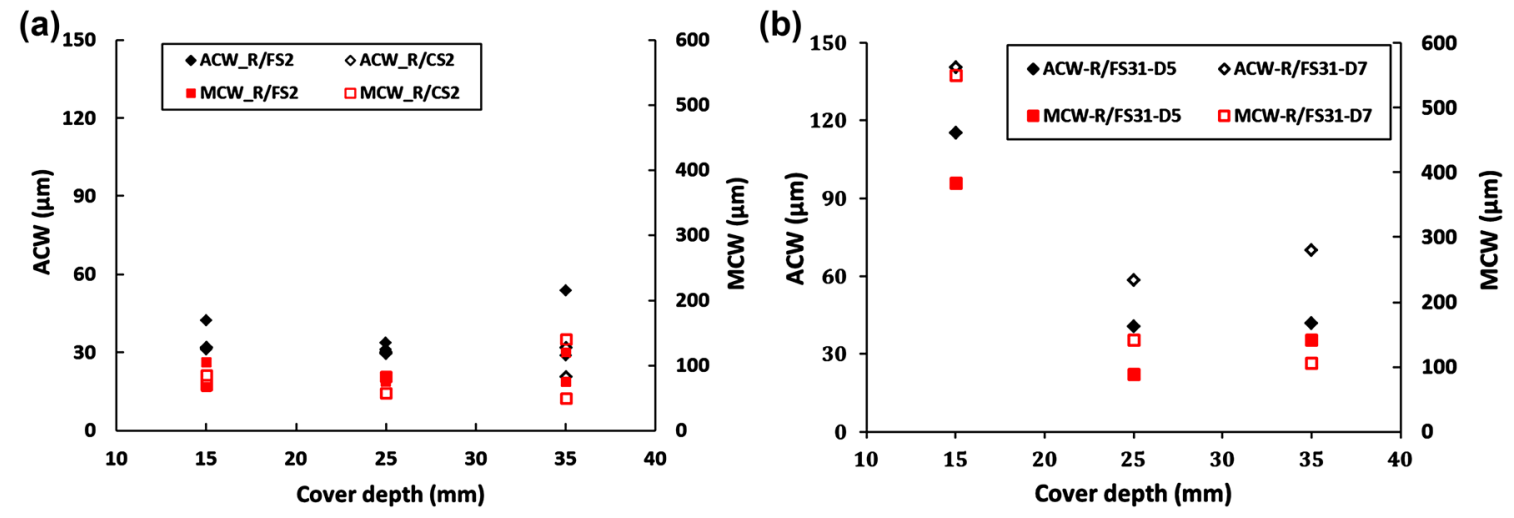

Fig. 3 Relationship between average crack width (ACW), maximum crack width (MCW) and cover depth of R/SHCC specimens.

(a)
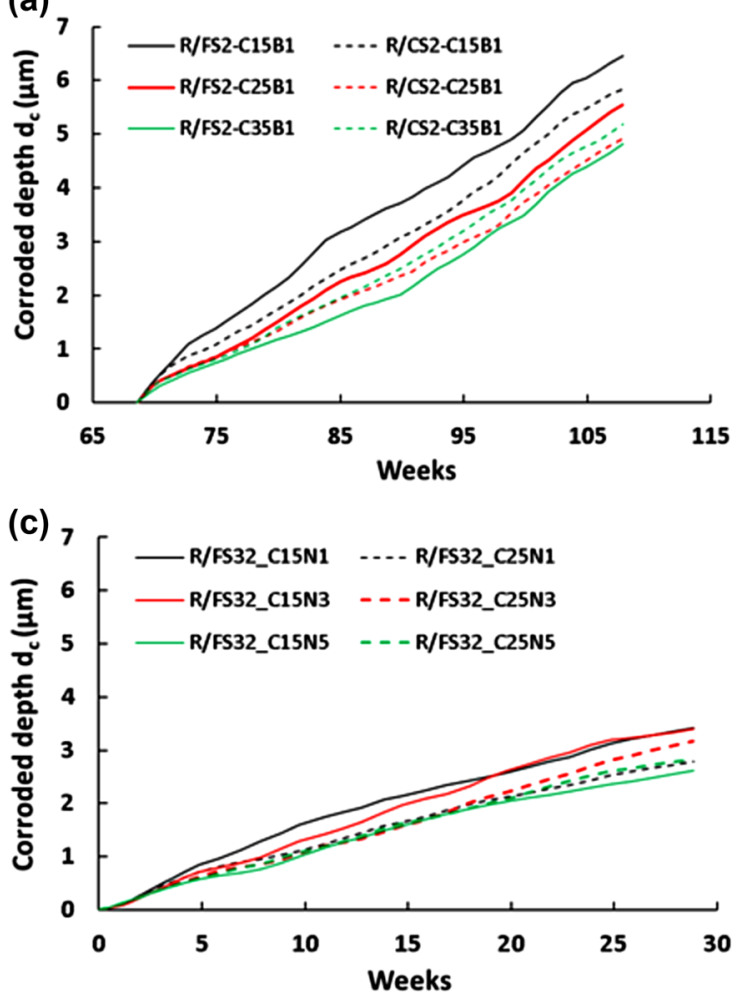

(b)

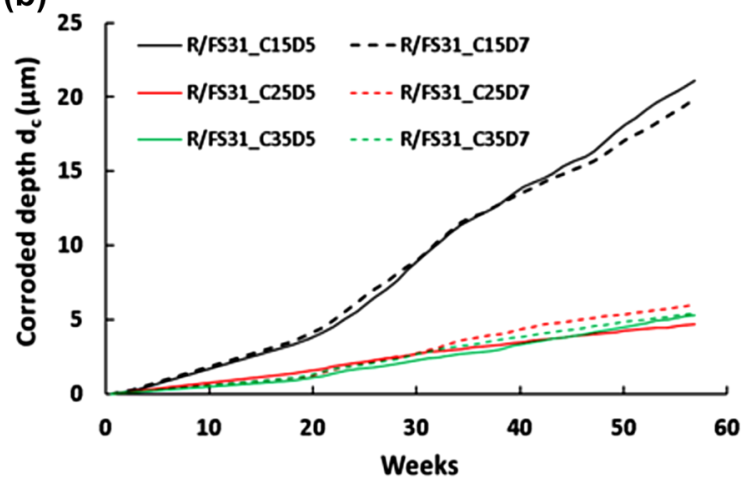

(d)

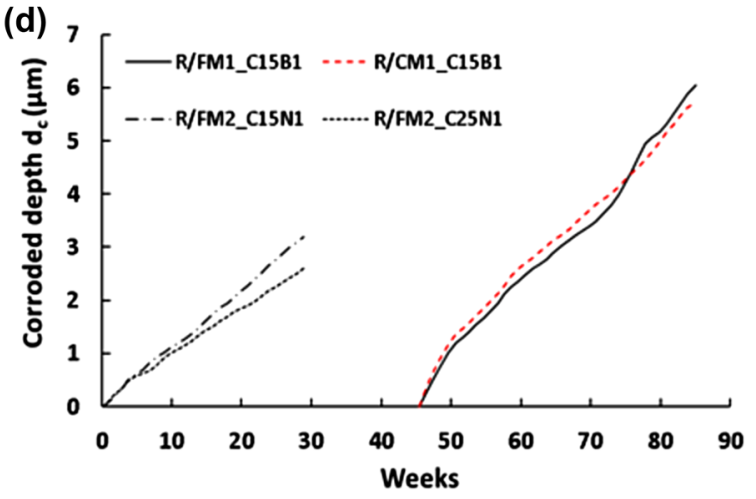

Fig. 4 Obtained corroded depths of steel bars in different R/SHCC and R/mortar specimens in accelerated corrosion test.

Note that Fig. 6b shows the steel bar before cleaning and Fig. 6c shows the same steel bar after cleaning with $\mathrm{HCl}$ acid.

Contrary to R/SHCC specimens, it appears that macro-cell corrosion occurred in all $\mathrm{R} /$ mortar specimens, with a typical one shown in Fig. 7. The limited number of cracks and larger crack widths in mortar specimens (Fig. 7a) are believed to be the reason for macro-cell corrosion. In this case the ion concentration is likely localized in the position of large cracks. In macro-cell corrosion the distance between anode and cathode is larger, resulting in localized attack of ions and formation of deeper corrosion. Steel capacity is clearly more significantly reduced when the corroded depths are greater. Greater corrosion depths are visible in Fig. 7c after cleaning the steel bar. Figure $7 \mathrm{~b}$ shows the steel bar before cleaning and Fig. $7 \mathrm{~d}$ shows the same, clean steel bar surface at the opposite side of cracks.

\subsection{Loss of Yield Force and Pitting in Steel Bars Due to Corrosion}

After cleaning the corroded steel bars, the tensile yield force was also determined in FS32 and FM2 specimens as reported in Fig. 8. Virgin steel bars were also tested for the reference yield force capacity $\left(F_{y}\right)$. Equation (6) was used to find the calculated yield force capacity $\left[F_{y}(\mathrm{Cal})\right]$ of corroded steel bars. All the steel bars were tested under uniaxial tensile testing to find the experimental yield force capacity $\left[F_{y}(\operatorname{Exp})\right]$ which is the remaining yield capacity of the corroded steel bars. In all cases the yield force capacity from the tensile test was found to be lower than the calculated capacity. The reasons include lack of calibration of the parameters as described in the previous section, but dominantly the localised nature of actual corrosion as opposed to the assumption of uniformly distributed corrosion damage in the calculated values. 

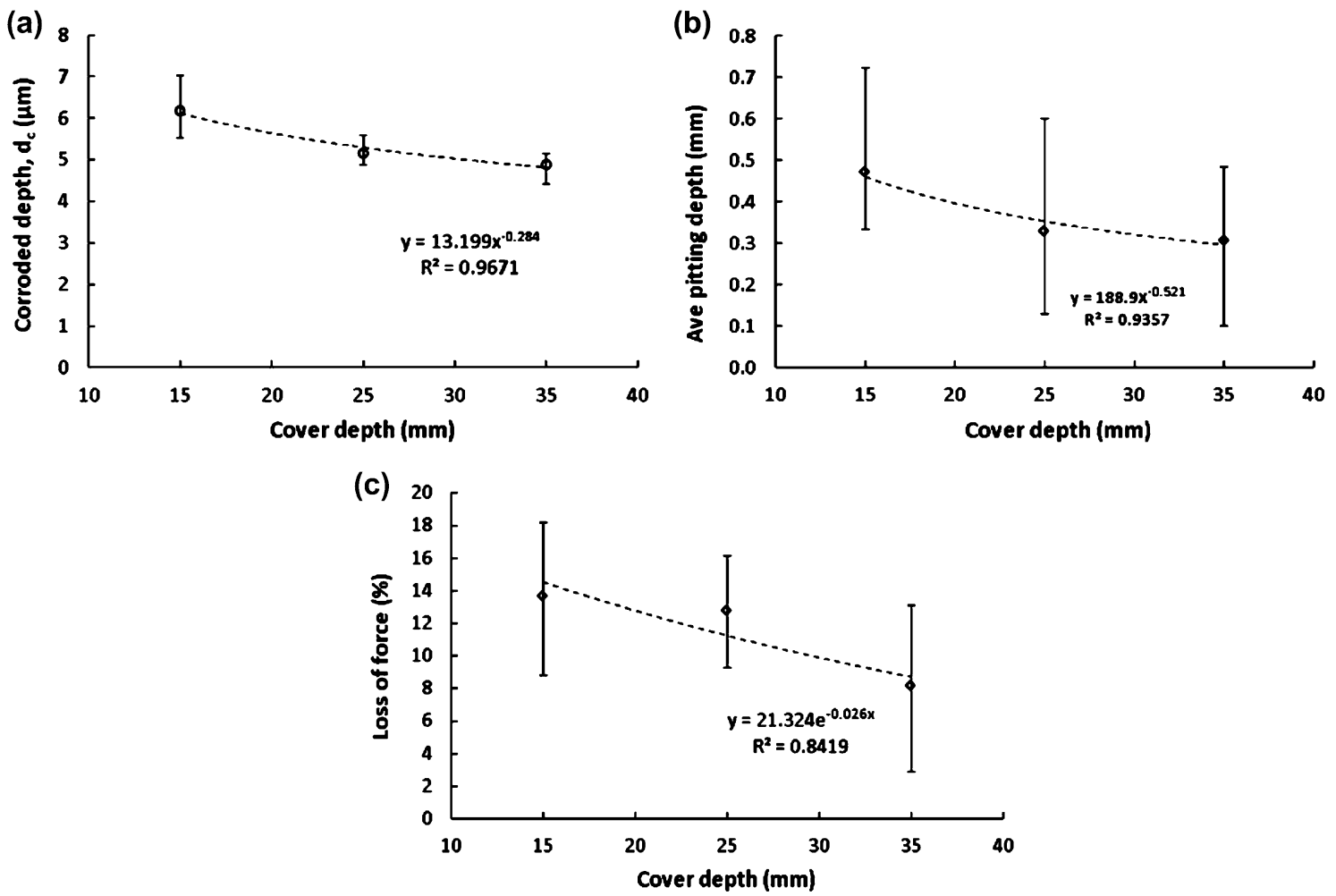

Fig. 5 Relationship between corroded depths, actual pitting depths, loss of yield force with respect to the cover depth of R/FS2 \& CS2 specimens.

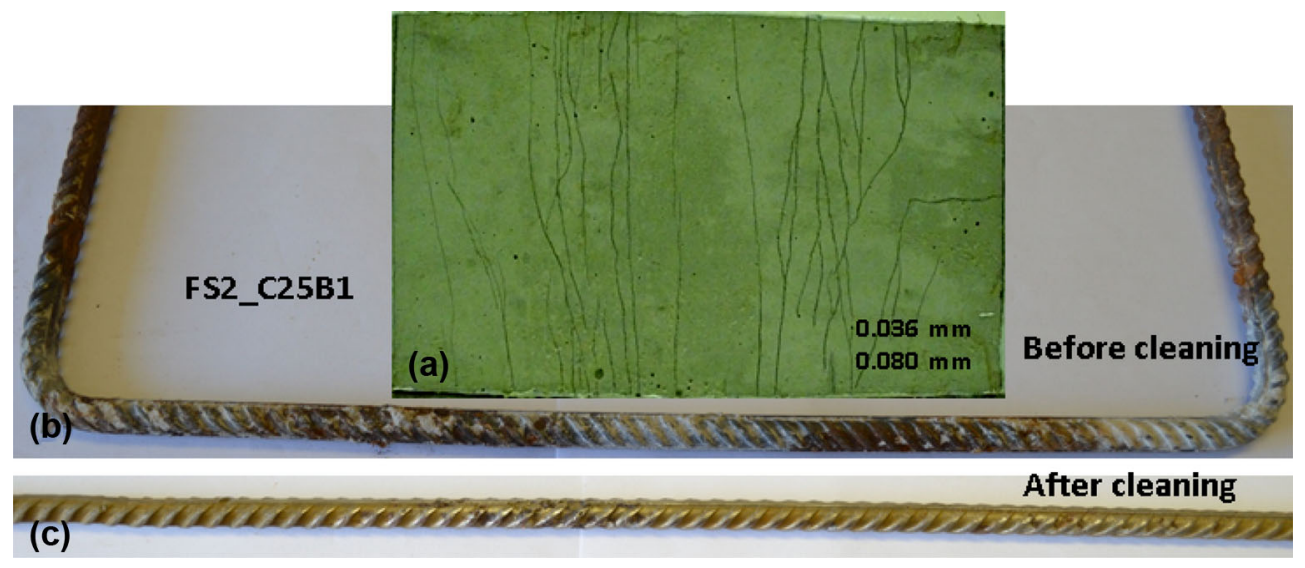

Fig. 6 Inspection of corrosion damage in an R/SHCC specimen.

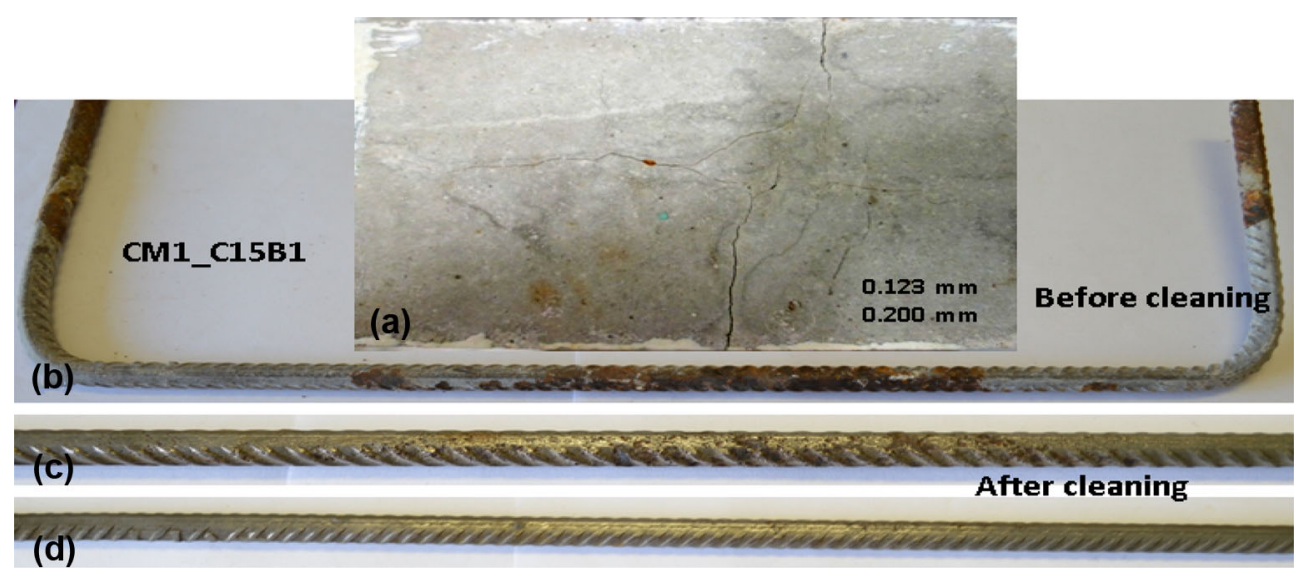

Fig. 7 Inspection of corrosion damage in an R/mortar specimen. 


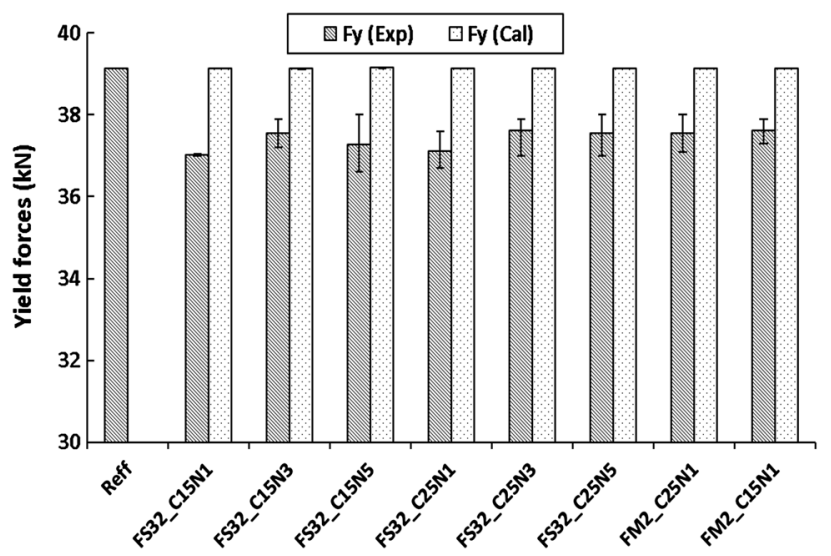

Fig. 8 Calculated and experimental yield forces of steel in $\mathrm{R} / \mathrm{FS} 32$ and R/FM2.

From Fig. 8 it is interesting to see that the experimental residual yield force capacity for SHCC specimens with exactly the same exposure times is greater for N3 and N5 specimens than for N1. Higher standard variations are seen in the N5 specimens. In case of C15 specimens, 5.4, 4 and $4.7 \%$ lower steel yield force were observed in N1, N3 and N5 specimens in comparison with the virgin steel. Similarly for $\mathrm{C} 25$ specimens, the losses of yield forces were 5, 3.9 and $4 \%$ respectively for N1, N3 and N5 specimens than virgin steel. So, with the limited data set reported here, it is noticed that there is a trend of increasing retained yield force for smaller crack spacing. This is in agreement with Fig. 4c, i.e. smaller corroded depth, more distributed corrosion and lower pitting depth. Also, a slightly higher retained yield force is found for the larger cover of $25 \mathrm{~mm}$, than for the specimens with $15 \mathrm{~mm}$ cover. No noticeable difference was observed in FM2 for different cover depth of the N1 specimens.

Measured actual pitting depths $\left(d_{p}\right)$ in the steel bars are shown in Figs. 9a-d. Since the corrosion rates of the specimens were low, the pitting depths were also low. Accurate measurement of these depths (see Fig. 2b) is complicated by pitting shape and size, despite the high dial gauge resolution $(10 \mu \mathrm{m})$. Because of the sensitivity of measuring these small pitting depths, not all pitting depths were measured, but the deeper pitting depths (larger than $10 \mu \mathrm{m}$ ) in the steel bars were chosen by visual inspection. A minimum of three to a maximum of six pitting depths on each steel bar were measured and their average value is reported in Fig. 9, while the minimum and maximum values of these 3-6 largest pitting depths are indicated by error bars. It is clear that the average pitting depths in the FS2 and CS2 specimens that were exposed for a longer time, are higher compared with those in the FS31 and FS32 specimens with lower exposure durations. In SHCC, lower pitting depths were observed for larger cover depth of the steel bar. An unexpected result is that D7 specimens had marginally lower pitting depths than D5 specimens. In FS31, at D5 level, almost 35\% and 43 and at D7 level, almost 66 and 5\% lower pitting depths were observed in $\mathrm{C} 25$ and $\mathrm{C} 35$ specimens than in $\mathrm{C} 15$ specimens. However, because of the lower corrosion damage in the steel bars, no strong correlations were found for different sand type and number of notches in the R/SHCC specimens tested here.

Pitting area in the steel bars were also measured and reported in Fig. 10. Because of the difficulty of measuring the pitting area, steel bars were selected from only FS2, CS2 and FS31 specimens. After cleaning the steel bars, pitting areas were marked on the steel surface as circular, rectangular and trapezoidal shapes. A Vernier scale was then used to measure the dimensions of the marked areas. The pitting areas on the steel surface were added together per steel bar. It is clear from Fig. 10 that a larger number of cracks in the specimens in the gauge length of $200 \mathrm{~mm}$, cause lower total pitting area.

Figure 11 shows a relationship between average pitting depths and corrosion-induced loss of tensile yield force in R/FS31 and R/FS32 specimens. Note that these are the average values of three specimens for the same cover depth. An upward trend in loss of yield force with increased pitting depth is clear. Of importance in rebar yield force is the reduction in its cross-sectional area, which is clearly not represented by the pitting depth only, in light of the rather poor correlations shown in the figure. More accurate representation of loss of cross-sectional area is required to improve correlation with, and estimation of corrosion damage to steel reinforcement. It is also important to note that the steel bars used in R/FS2 and R/CS2 specimens were bent to have the U-shape shown in Fig. 6, while in other cases steel bars were straight. The purpose was to facilitate the necessary cable connection during the corrosion rate measurement on these specimens. However, for the tensile testing the bent portions of these bars were straightened again. It is reported by the Choi et al. (2003) that this procedure (bend and straighten) can cause significant loss of yield force $(20-25 \%)$ of the steel bar. For this reason higher loss of yield force was found in the steel bars of R/FS2 and $\mathrm{R} / \mathrm{CS} 2$ specimens. However, these specimens are not included in Fig. 11, since the properties of these steel bars were influenced by the described bending process.

\subsection{Chloride Content in the R/SHCC and R/ Mortar Specimens}

Total chloride profiles determined by XRF are shown in Fig. $12 \mathrm{a}-\mathrm{d}$. Note that the different types of specimens were tested after different durations of exposure, which are also shown in the figures. The typical trend of high chloride content at the surface, and gradual reduction with depth is clear in the graphs. From the results found in this research it can be said that the maximum total chloride content for this specific matrix can be up to $1.8 \%$ of binder weight. The chloride profile through the whole depth of both cracked and un-cracked SHCC specimens is also shown in Fig. 12c. For the un-cracked (UC) chloride profile, powder samples were collected in $5 \mathrm{~mm}$ layer intervals up to a depth of $50 \mathrm{~mm}$ on the specimen surface where there were no cracks. In this regard, a single notch specimen from FS32 type SHCC was chosen. It can be seen that the chloride penetration is significantly lower un-cracked SHCC and from a depth of about 

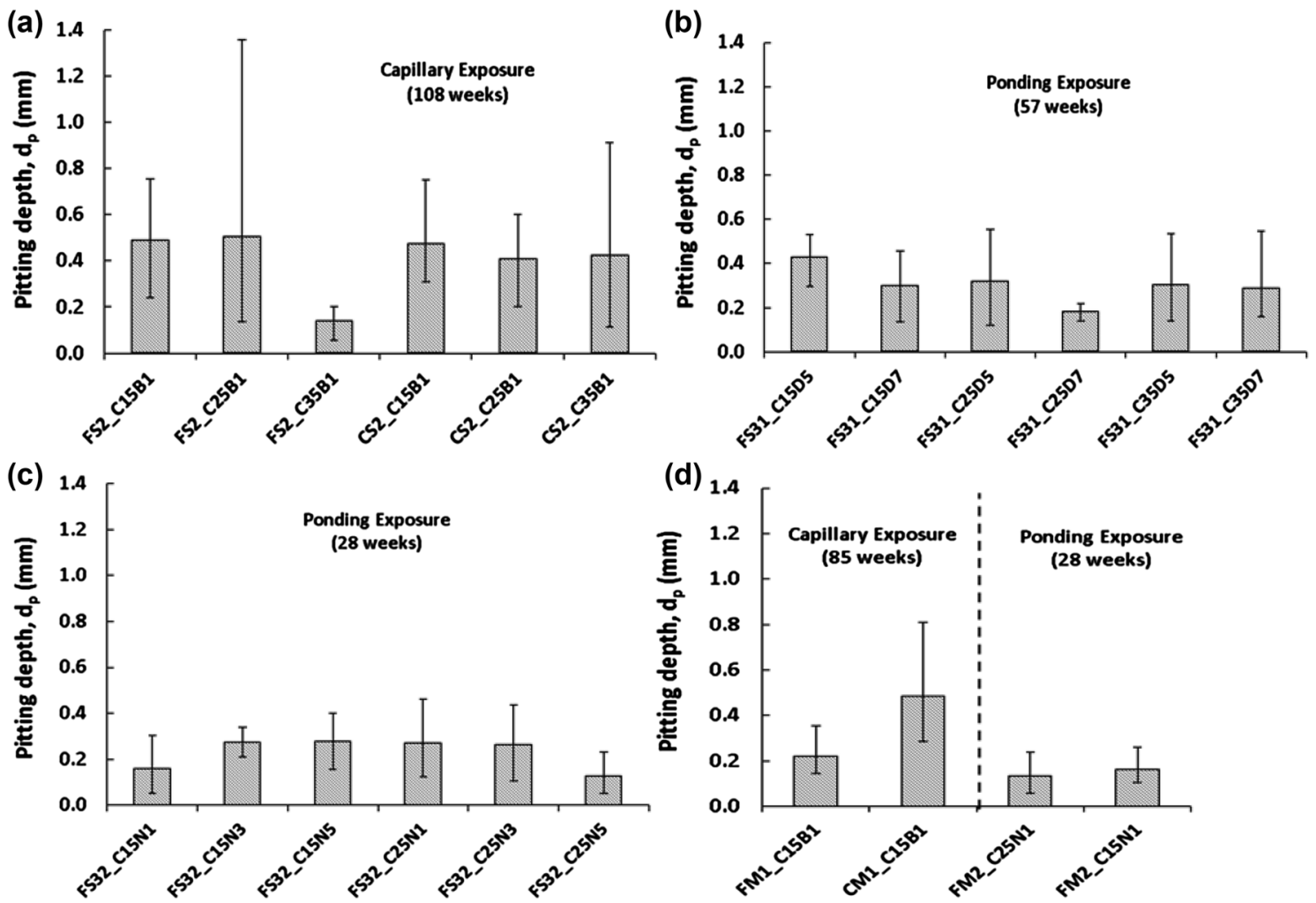

Fig. 9 Measured pitting depth due to corrosion of steel in R/SHCC and R/mortar specimens.

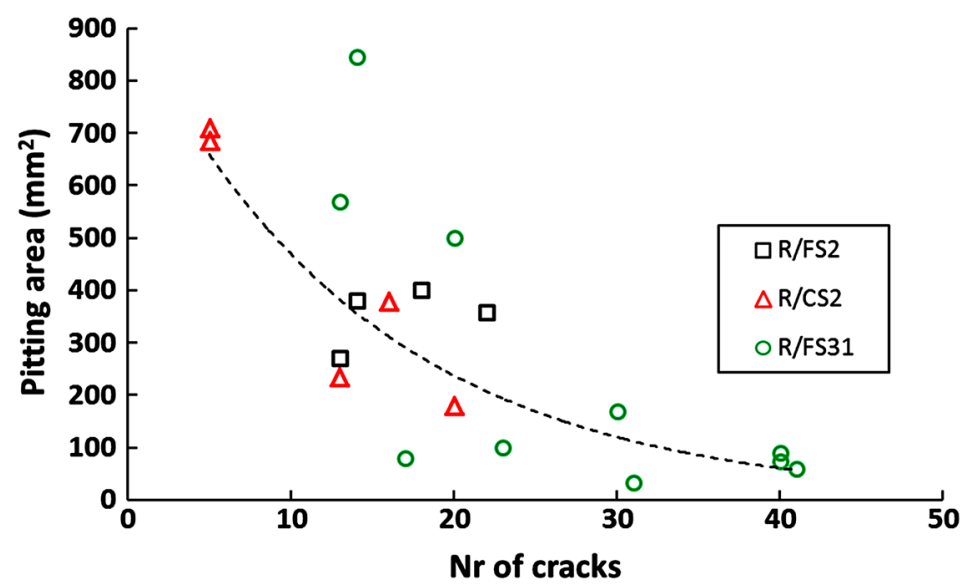

Fig. 10 Actual pitting area in the corroded steel bars versus number of cracks in R/SHCC specimens.

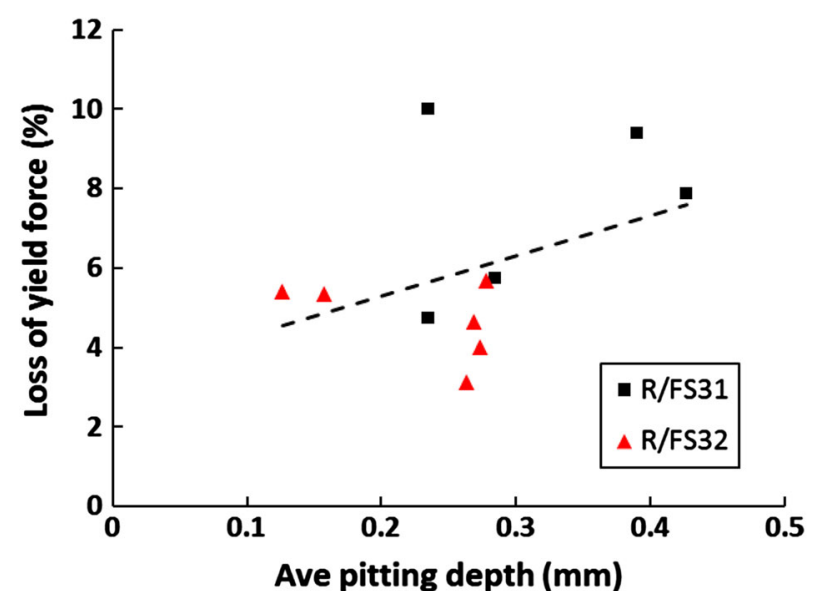

Fig. 11 Influence of average pitting depths on loss of yield force of steel in R/SHCC.
$20 \mathrm{~mm}$ a low total amount of chloride is found in the specimen.

\subsection{Relationship Between XRF and Chemical Total Chloride}

For the chloride profiling, the XRF method was chosen for its ease and short duration. To verify the outcome of the XRF results, chemical analysis according to the RILEM TC178 recommendation (2002a) was also followed to determine the total chloride content in the specimens. A total of 30 different samples which were tested with XRF were used also in the chemical analysis. Figure 13 shows the relationship between the XRF and total chloride chemical test results. A linear correlation is found, which deems XRF to be a suitable alternative for the determination of total chloride profiling in SHCC. 

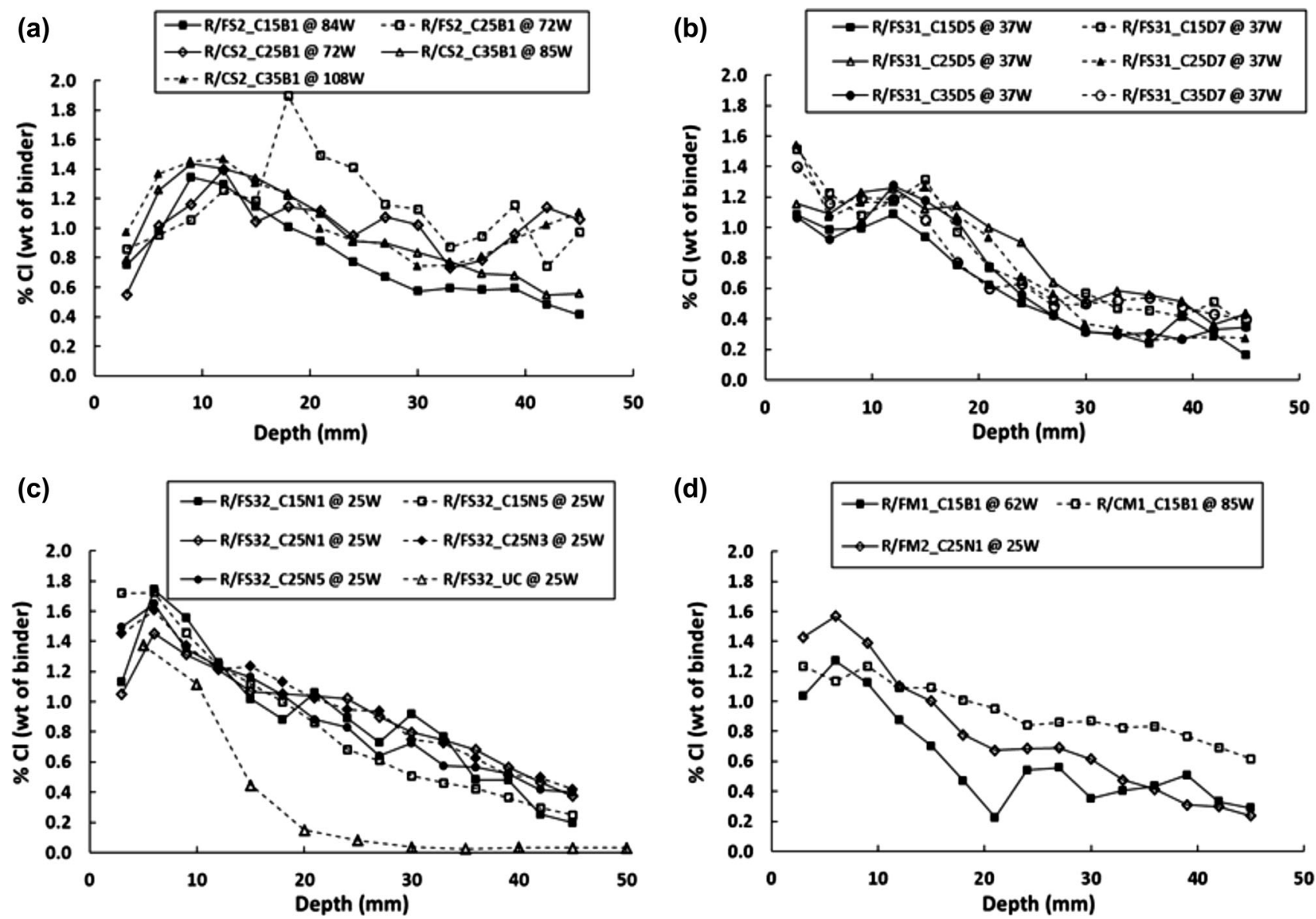

Fig. $12 \mathrm{XRF}$ total chloride profile obtained in different R/SHCC and R/mortar specimens up to a depth of $45 \mathrm{~mm}$, at different ages in weeks (W).

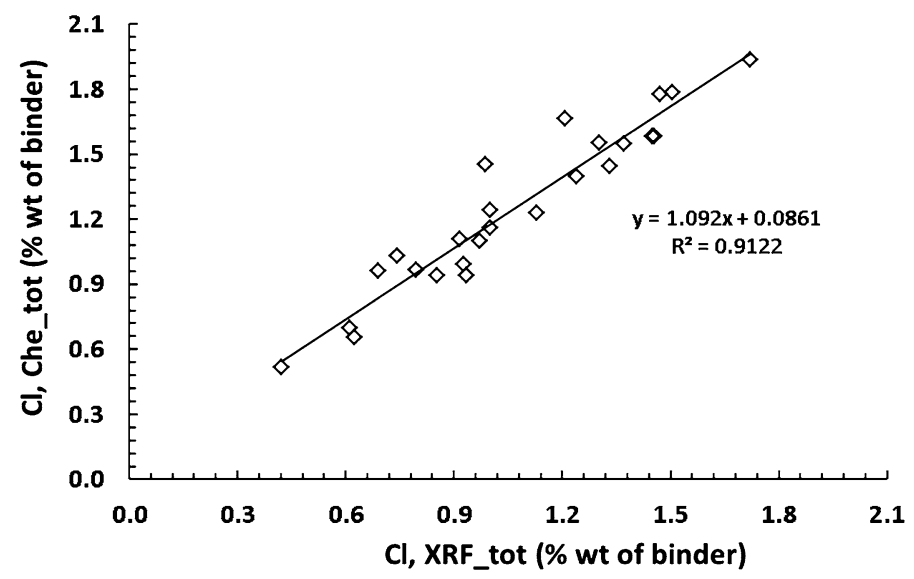

Fig. 13 Relationships between XRF and chemical analysis of total chloride content.

\subsection{Total and Free Chloride Content at Different Depth of Specimens}

A total of 42 samples were tested by chemical analysis for determining the free chloride content according to RILEM TC178 (2002b). The relationships between the free and total chloride measurement results from the chemical analysis, as well as those from XRF total chloride measurement are shown in Fig. 14. Note that the chloride content showed there are the average chloride content in the specimens from the top surface to bottom surface of each individual steel bar. For instance, chloride content in a C15 specimen steel bar was determined by taking the average XRF chloride value from a depth of 15-25 mm reported in Fig. 12. Lower chloride content (both total and free) was found in the mortar specimens. This may be explained by the specimens' lower total crack width. Although multiple fine cracks were found in the SHCC specimens, the total crack width in SHCC specimens were significantly higher than in the mortar specimens. Another reason is that when drilling was performed to collect the powder samples of mortar specimens, only one crack was covered by the drill diameter $(16 \mathrm{~mm})$ while in SHCC 2-4 cracks were covered due to their small 


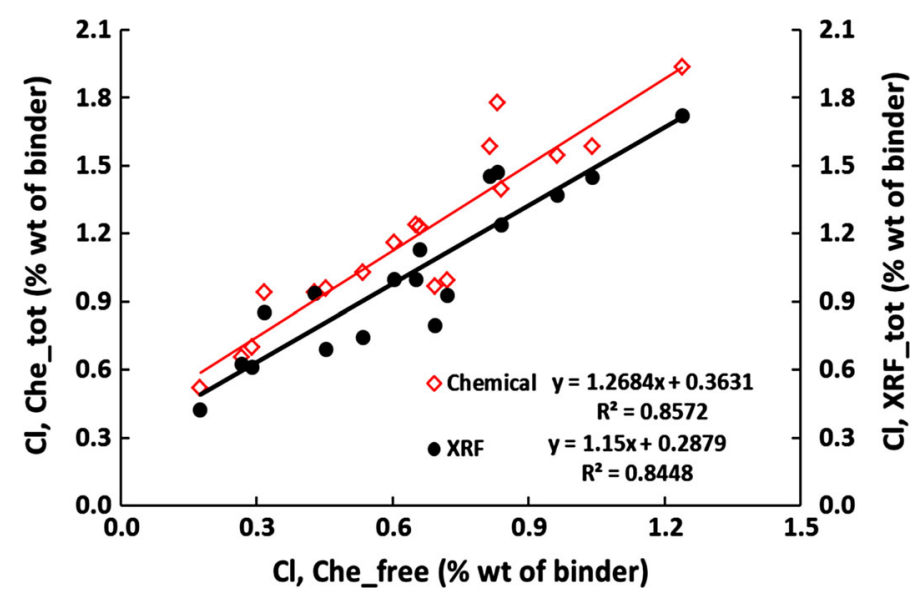

Fig. 14 Relationships between XRF and chemical analysis of total and free chloride content.
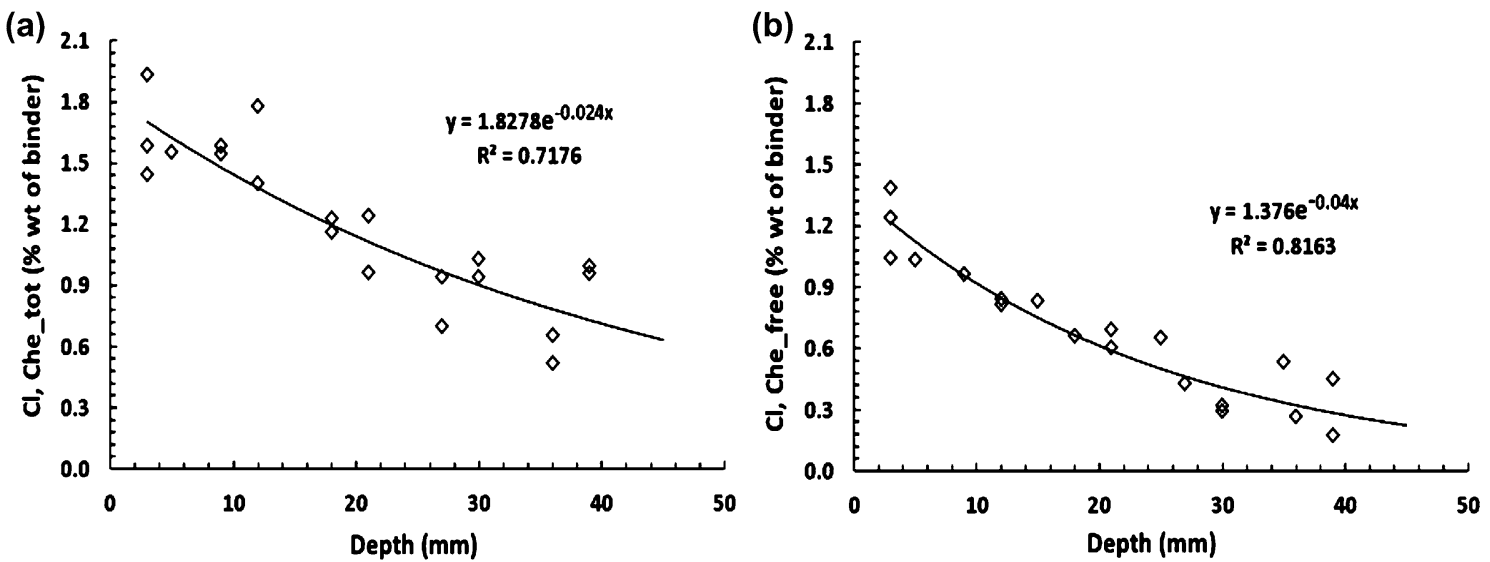

Fig. 15 Level of chemical total chloride contents at different depths of R/SHCC specimens.

spacing. In this regard, two-dimensional chloride profiling is envisaged in future work, to improve the characterisation of chloride content distribution in cracked cement-based composites. Also, the presence of fibre in the SHCC matrix may form pores which ultimately help chloride ions to be stored, and as a result higher free chloride concentrations can be expected in SHCC than in mortar specimens.

Relationships were also drawn from the chemical testing of total and free chloride content with respect to the depths in cracked R/SHCC specimens as shown in Figs. 15a-b. Both chloride contents appear to form an exponential relationship with depth in cracked R/SHCC.

In this research the difference between the chemical total and free chloride at different depths in SHCC specimens was found to be in a range of $5-65 \%$. In case of $\mathrm{NC}$, this difference was found to be in a range of $10-53 \%$ by Liu (1996). So, the results obtained in this research show a similar trend in the matrix of SHCC used here with that of NC.

\section{Discussion of Results}

Typically, the corrosion rate/current is captured by the electric current (or migration of ions) driven by the potential differences between the cathodic and anodic areas (Markeset and Myrdal 2008). So, the position of the cathode and anode in the steel bar is very important. When the number of cracks is limited and the crack spacing is large, the distance between anode and cathode area is large and significant pitting corrosion can form in the steel bar due to the fact that the smaller anode area in the limited crack region is fed by the large cathode area. This can be seen in the Fig. 16, where a trend is found of larger pitting depths forming when average crack spacing in the specimen is increased. On the other hand when there are many cracks and cracks are spaced closer together, a lower cathode: anode ratio exists. When the cathode area reduces, less $\mathrm{OH}^{-}$becomes available for the reaction with $\mathrm{Fe}^{+}$in the anodic area and as a result a lower corrosion rate can be expected in the steel bar.

Depending on the availability of oxygen and moisture in the specimen, the corrosion rate of steel can vary with time. It is also difficult to know whether the steel is in an active or passive state of corrosion inside concrete, since it is not possible to see the real corrosion damage in the steel embedded in the concrete. As a result the assumption of Stern and Geary constant (B) value may under or overestimate the real corrosion rate in steel bars. Therefore, the 


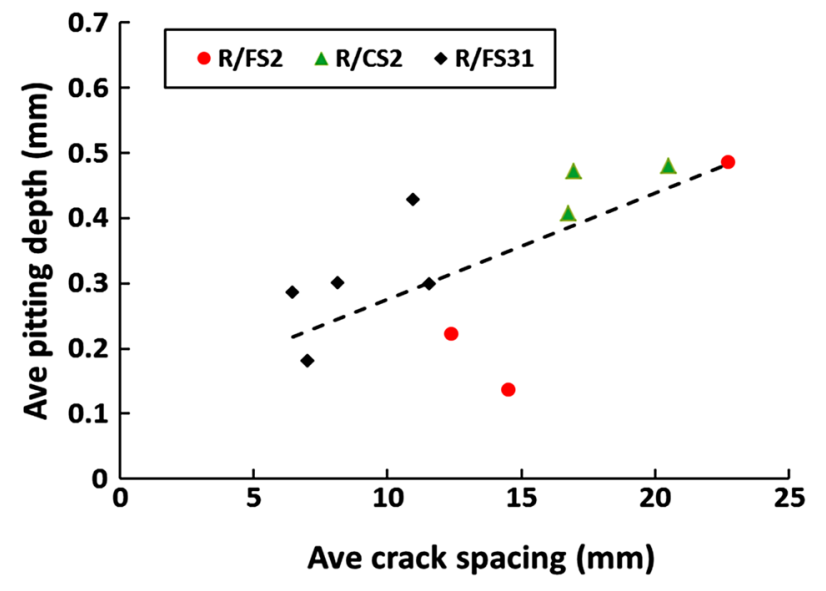

Fig. 16 Influence of average crack spacing in average pitting depths in steel bar.

corrosion in steel is indeed a complex process and depends on many factors.

\subsection{Influence of Chloride Content and Mass Loss of Steel in Corrosion}

Figure 17 shows a relationship between the estimated corroded depths with total and free chloride contents at the surface of steel bars in the different R/SHCC specimens. Free chloride content appears to be more representative of the corrosion of steel bars. Note that in chloride content testing only selected specimens were used from the different SHCC reported here. So the chloride content corresponding to the corroded depths reported in Figs. 4, 5 may not be seen in Fig. 17.

Measured corrosion rate using the Coulostatic technique, reported as the calculated corroded depth here, was also verified with the actual mass loss due to corrosion of steel in $\mathrm{R} / \mathrm{FS} 32$ and R/FM2 specimens and the outcome is shown in Fig. 18. Note that the values reported here are the average of three SHCC and two mortar specimens for the same number of notches and for two different cover depths. It appears that the mass loss of steel is exponentially increased as the corroded depth (in Fig. 18a) and loss of yield force (in Fig. 18b) increase in the specimens. It is postulated that the measured corrosion rate as reported by corroded depths using the Coulostatic method is relevant since it is expected that the mass loss of steel increases as the corrosion rate increases. Note that the exposure period for R/FS32 and R/FM2 was relatively short ( 28 weeks) and because of that the magnitudes of the corroded depth, yield force loss and mass loss values from the different specimens are small.

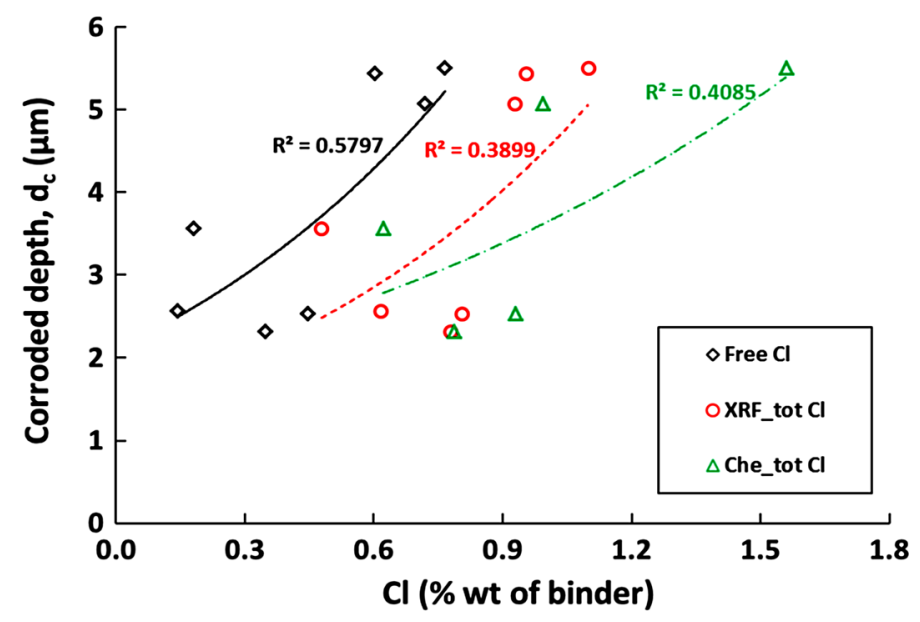

Fig. 17 Relationship between corroded depths and different chloride content.
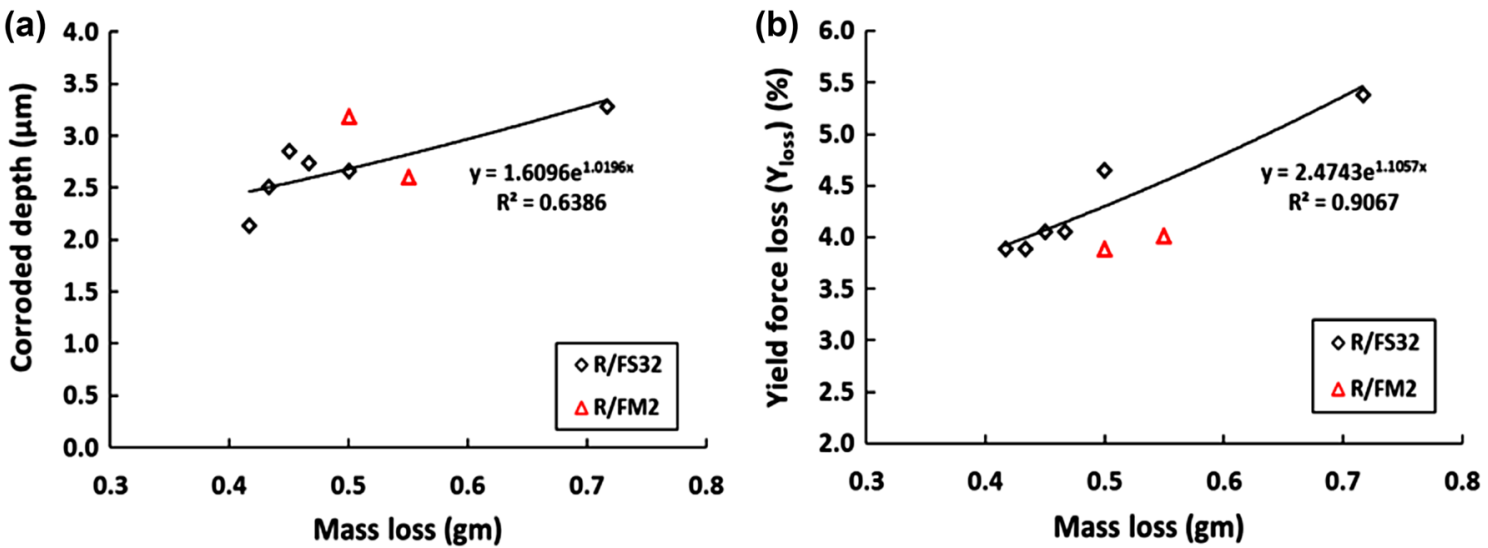

Fig. 18 Measured corroded depths and actual mass loss of steel bars of R/FS32 and R/FM2 specimens. 
(a)

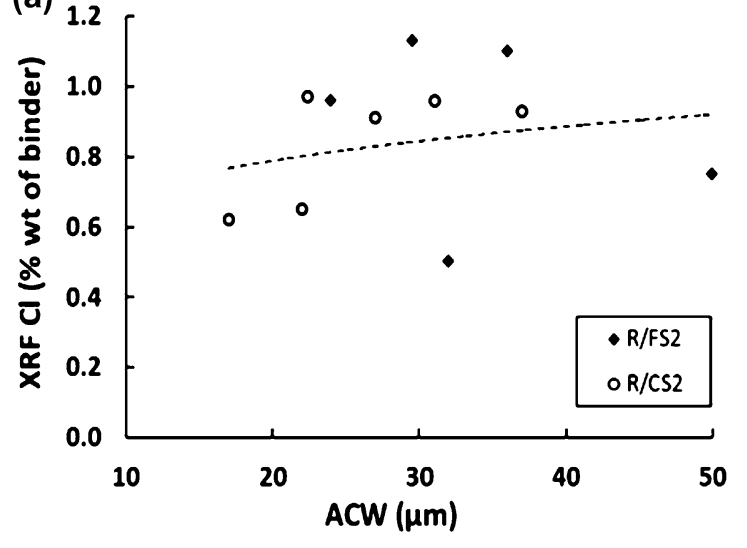

(b)

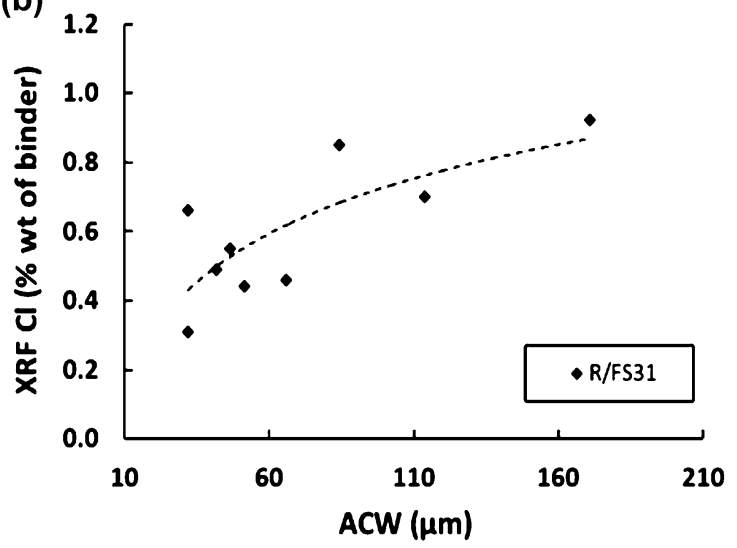

Fig. 19 Relationship between total chlorides (Cl) determined by XRF and average crack widths (ACW) in the R/SHCC specimens.

However, the difference between the lower and upper values of corroded depth and yield force loss in Fig. 18a, b are about 35 and $28 \%$ respectively, which are significant.

\subsection{Effect of Cracking in Chloride Penetration}

The influence of average crack widths on total chloride penetration measured by XRF was also observed in $\mathrm{R} / \mathrm{SHCC}$, as shown in Fig. 19a, b. No clear relationship appears to exist between crack width and chloride content for the average crack widths below $0.05 \mathrm{~mm}$ in Fig. 19a. In Fig. 19b, a trend of higher total chloride with higher average crack width is apparent. To interpret these apparently contradicting results, it must be noted that the total exposure time of the specimens in Fig. 19a was 108 weeks, i.e. near double the exposure time of those specimens shown in Fig. 19b. Thereby, it is likely that the influence of crack widths in the Fig. 19a diminish through gradual chloride ingress into the matrix from the crack faces subsequent to quick ingress into the cracks. Also, two dimensional chloride profiling will be used in future work, in order to more accurately relate crack width and chloride concentration in cracked SHCC. Chloride ingress is also related to the matrix diffusivity. Furthermore, it should also be kept in mind that two different chloride exposures of capillary absorption and ponding (see Sect. 3.4) might influence the chloride profiles in the respective specimens.

\section{Conclusions}

This research work has revealed some important parameters which are necessary for durability modelling of chloride induced corrosion in cracked SHCC. The Coulostatic technique used here is found to reasonably represent mass loss of steel due to corrosion, although no attempt to improve calibration has been made here. In terms of the corrosive deterioration for the observed and enforced (notched) crack properties in $\mathrm{R} / \mathrm{SHCC}$, the following conclusions can be drawn from the experimental work of this research:

- Average and maximum crack widths and crack spacing in the R/SHCC are smaller for larger cover depth of the steel bar. From the particular type of SHCC used in this research, it appears that a $25 \mathrm{~mm}$ cover depth is the threshold cover depth for limiting the crack width in $\mathrm{R} / \mathrm{SHCC}$.

- Mass loss, pitting depth and loss of yield force are considered to be low in all specimens, despite up to 108 weeks of cyclic wetting and drying chloride exposure. After 108 weeks of such exposure, a maximum pitting depth of $1.4 \mathrm{~mm}$ was found in the $10 \mathrm{~mm}$ diameter steel bars, with the average pitting depth in the range $0.1-0.5 \mathrm{~mm}$. For lower exposure durations, the average pitting depths were lower at $0.1-0.4 \mathrm{~mm}$ after 57 weeks, and $0.1-0.3 \mathrm{~mm}$ after 28 weeks of cyclic chloride exposure. This led to a maximum loss of yield force of the bars of about $17 \%$ in a CS2_C15B1 specimens.

- In chloride-induced corrosion performed here, higher corroded depths (measured by a Coulostatic method), actual measured pitting depths, and higher loss of yield force in the steel were found in the specimens with cover depth of $15 \mathrm{~mm}$ than for 25 and $35 \mathrm{~mm}$ cover depths. No significant difference was observed in the specimens with 25 and $35 \mathrm{~mm}$ cover depths.

- A significant reduction in tensile strain capacity was found for SHCC produced with coarse sand (CS2) compared with fine sand. However, there were no significant differences in the pitting depths and loss of yield force of steel in coarse sand specimens CS2 and CM1 than in fine sand specimens FS2 and FM1.

- Free chloride content in the specimen at the level of the steel bar appears to correlate better with the corrosion damage than total chloride content. However, while the role of chloride in corrosion initiation has been studied widely, its role in corrosion propagation and corrosion rate must be investigated further.

- The XRF method can be an alternative method for chemical testing in determining total chloride content in SHCC. Both total and free chloride content reduced with depth into the specimens and the difference between chemical total and free chloride content was found to be in the range of $5-65 \%$, depending on the depth in the specimen. 
- The actual mass loss of steel bars is related to the corroded depths and loss of yield force of R/FS32 and $\mathrm{R} / \mathrm{FM} 2$ specimens. The pitting depth in the steel bars was larger for larger average crack spacing in the $\mathrm{R} / \mathrm{SHCC}$ specimens.

- A larger number of cracks, associated with finer crack spacing, lead to significantly lower corrosion damage in $\mathrm{R} / \mathrm{SHCC}$.

\section{Open Access}

This article is distributed under the terms of the Creative Commons Attribution 4.0 International License (http:// creativecommons.org/licenses/by/4.0/), which permits un restricted use, distribution, and reproduction in any medium, provided you give appropriate credit to the original author(s) and the source, provide a link to the Creative Commons license, and indicate if changes were made.

\section{References}

Altoubat, S., Maalej, M., \& Shaikh, F. U. A. (2016). Laboratory simulation of corrosion damage in reinforced concrete. International Journal of Concrete Structures and Materials, 10(3), 383-391.

Andrade, C., \& Alonso, C. (2004). Test methods for on-site corrosion rate measurement of steel reinforcement in concrete by means of the polarization resistance method. $\mathrm{Ma}$ terials and Structure, 37, 623-643.

Angst, U., Elsener, B., Larsen, C. K., \& Vennesland, Ø. (2009). Critical chloride content in reinforced concrete-a review. Cement and Concrete Research, 39(12), 1122-1138.

Bashir, H., Osman, B. H., Wu, E., Ji, B., \& Abdulhameed, S. S. (2017). Repair of pre-cracked reinforced concrete (RC) Beams with openings strengthened using FRP sheets under sustained load. International Journal of Concrete Structures and Materials, 11(1), 171-183.

Blagojević, A. (2016). The Influence of Cracks on the Durability and Service Life of Reinforced Concrete Structures in relation to Chloride-Induced Corrosion: A Look from a Different Perspective. PhD Thesis, Delft University of Technology, Delft, The Netherland.

Broomfield, J. P. (2007). Corrosion of steel in concrete understanding, investigating and repair. Book 2nd edition, Taylor \& Francis, USA \& Canada.

Choi, H., Kim, H., Seo, D., \& Kang, K. (2003). The study on the capacity transform and alternative plan of reinforcing bar with straightening after bending. Journal of the Architectural Institute of Structural Systems, 19(9), 181-188.

Djerbi, A., Bonnet, S., Khelidj, A., \& Baroghel-Bouny, V. (2008). Influence of traversing crack on chloride diffusion into concrete. Cement and Concrete Research, 38, 877-883.

German, M., \& Zaborski, A. (2011). Numerical analysis of chloride corrosion of reinforced concrete. Technical Transections, 3, 47-59.
Glass, G. K. (1995). An assessment of the coulostatic method applied to the corrosion of steel in concrete. Corrosion Science, 37(4), 597-605.

Gonzalez, J. A., Cobo, A., Gonzalez, M. N., \& Feliu, S. (2001). On-site determination of corrosion rate in reinforced concrete structures by use of galvanostatic pulses. Corrosion Science, 43(4), 611-625.

Hausmann, D. A. (1967). Steel corrosion in concrete. Materials Protection, 6, 19-23.

Huang, Q. (2006). Influence of cracks on chloride-induced corrosion in reinforced concrete structures. MSc thesis, Chalmers University of Technology, Sweden.

Kobayashi, K., Iizuka, T., Kurachi, H., \& Rokugo, K. (2010). Corrosion protection performance of high performance fiber reinforced cement composites as a repair material. Cement and Concrete Composite, 32, 411-420.

Kobayashi, K., \& Rokugo, K. (2013). Mechanical performance of corroded RC member repaired by HPFRCC patching. Construction and Building Materials, 39, 139-147.

Li, V. C. (2012). Tailoring ECC for Special Attributes: A Review. International Journal of Concrete Structures and Materials, 6(3), 135-144.

Liang, M. T., Huang, R., Feng, S. A., \& Yeh, C. J. (2009). Service life prediction of pier for the existing reinforced concrete bridges in chloride-laden environment. Journal of Marine Science and Technology, 17(4), 312-319.

Liu, Y. (1996). Modelling the Time-to-Corrosion Cracking of the Cover Concrete in Chloride Contaminated Reinforced Concrete Structures. PhD thesis, Virginia Polytechnic Institute and State University, USA.

Markeset, G., \& Myrdal, R. (2008). Modelling of reinforcement corrosion in concrete- State of the art, COIN Project report no7, SINTEF Building and Infrastructure, ISBN 1891-1978.

Mihashi, H., Ahmed, S. F. U., \& Kobayakawa, A. (2011). Corrosion of reinforcing steel in fibre reinforced cementitious composites. Journal of Advanced Concrete Technology, 9(2), 159-167.

Mohammed, T. U., Otsuki, N., Hisada, M., \& Shibat, T. (2001). Effect of crack width and bar types on corrosion of steel in concrete. Journal of Materials in Civil Engineering, 13, 194-201.

Pacheco, J., \& Polder, R. B. (2016). Critical chloride concentrations in reinforced concrete specimens with ordinary Portland and blast furnace slag cement. HERON, 61(2), 99-119.

Paul, S.C. (2015). The role of cracks and chlorides in corrosion of reinforced strain-hardening cement-based composites (R/SHCC), PhD Thesis, Stellenbosch University, Stellenbosch, South Africa.

Paul, S. C., Babafemi, A. J., Conradie, K., \& van Zijl, G. P. A. G. (2017). Applied voltage on corrosion mass loss and cracking behaviour of steel reinforced SHCC and mortar specimens. Journal of Materials in Civil Engineering. doi:10.1061/(ASCE)MT.1943-5533.0001807.

Paul, S. C., \& van Zijl, G. P. A. G. (2013). Mechanically induced cracking behaviour in fine and coarse sand strainhardening cement based composites (SHCC) at different 
load levels. Journal of Advanced Concrete Technology, 11, 301-311.

Paul, S. C., \& van Zijl, G. P. A. G. (2014). Crack formation and chloride induced corrosion in reinforced strain hardening cement-based composite (R/SHCC). Journal of Advanced Concrete Technology, 12, 340-351.

Paul, S. C., \& van Zijl, G. P. A. G. (2016). Chloride-induced corrosion modelling of cracked reinforced SHCC. Archives of Civil and Mechanical Engineering, 16(4), 734-742.

Pettersson, K. (1993). Corrosion of steel in high performance concrete. In Proceedings of the $3^{\text {rd }}$ International Symposium on Utilization of High Strength Concrete, Lillehammer, Norway (published by the Norwegian Concrete Association).

Rilem, T. C. (2002a). Testing and modelling chloride penetration in concrete. Analysis of total chloride content in concrete. Materials and Structure, 35, 583-585.

Rilem, T. C. (2002b). Testing and modelling chloride penetration in concrete. Analysis of water soluble chloride content in concrete. Materials and Structure, 35, 586-588.

Sahmaran, M., Li, V. C., \& Andrade, C. (2008). Corrosion resistance performance of steel reinforced engineered cementitious composite beams. ACI Materials Journal, 105(3), 243-250.
Schiessl, P., \& Raupach, M. (1997). Laboratory studies and calculations on the influence of crack width on chlorideinduced corrosion of steel in concrete. ACI Materials Journal, 94(1), 56-62.

Soltani, A., Harries, K. A., \& Shahrooz, B. M. (2013). Crack Opening Behavior of Concrete Reinforced with High Strength Reinforcing Steel. International Journal of Concrete Structures and Materials, 7(4), 253-264.

Tang, L., Utgenannt, P., \& Boubitsas, D. (2015). Durability and Service Life Prediction of Reinforced Concrete Structures. Journal of the Chinese Ceramic Society, 43(10), 1408-1419.

Wang, K., Jansen, D. C., Shah, S. P., \& Karr, A. F. (1997). Permeability study of cracked concrete. Cement and Concrete Research, 27(3), 381-393.

Wittmann, F. H., Wang, P., Zhang, P., Zhao, Tie-Jun., \& Betzung, F. (2011). Capillary absorption and chloride penetration in neat and water repellent SHCC under imposed strain. Paper presented at the $2^{\text {nd }}$ International RILEM Conference on Strain Hardening Cementitious Composites, Brazil, pp.165-172.

Yoo, D. Y., \& Yoon, Y. S. (2016). A review on structural behavior, design, and application of ultra-high-performance fiber-reinforced concrete. International Journal of Concrete Structures and Materials, 10(2), 125-142. 